\title{
The Conceptual Model of Influencing Factors and Influencing Mechanism on Team Decision-Making Quality Mediated by Information Sharing
}

\author{
Peihua Dai ${ }^{1,2}$ \\ ${ }^{1}$ Southwest Jiaotong University, Chengdu, China; ${ }^{2}$ Chongqing Technology and Business University, Chongqing, China. \\ Email: daiph128@sohu.com
}

Received August $15^{\text {th }}$, 2013; revised September $13^{\text {th }}, 2013$; accepted October $10^{\text {th }}, 2013$

Copyright (C) 2013 Peihua Dai. This is an open access article distributed under the Creative Commons Attribution License, which permits unrestricted use, distribution, and reproduction in any medium, provided the original work is properly cited.

\begin{abstract}
Searching for the influencing factors on team decision-making quality is the hot issue in academic circles and business circles. Based on summarizing the main influencing factors on team decision-making quality, this thesis divides the main influencing factors into team composition factors and team process factors and researches the internal relationship between them. Targeted at the field decision making, this thesis analyzes the influencing process of the main factors on decision-making quality, and constructs the conceptual model of "influencing factors-information sharing-decisionmaking quality". This model not only combines the main influencing factors correctly, but also exposes the "black box" between the influencing factors and decision-making quality in field decision making, which can make up for no relative research for the field decision making in the previous studies.
\end{abstract}

Keywords: Decision-Making Quality; Composition Factors; Process Factors; Information Sharing

\section{Introduction}

Studies of team decision-making originated from the researches of a small group in traditional social psychology. As more and more organization structures are formed by teams, the studies on team decision-making by industrial and organizational psychologists are more and more widely [1]. Lots of scholars researched the influencing factors on team decision-making from different viewpoints and got abundant achievements, such as the leadership's desire of power, team cohesion, individual levels of team members, team size, discuss form, team conflict, team communication and so on [2,3]. However, most of the scholars only investigated the effects of one or two factors on decision-making quality through empirical methods. There has been a lack of systematical review and classification in the main influencing factors, and a lack of researches on the internal relationship between the main factors.

When researching the influencing mechanism of the main factors on team decision-making performance, scholars usually selected mediators from the paths of information communication and emotional response, such as team transactive memory, task reflexivity, team mental model, team cohesion and so on [4]. But all these mediators need the long time to accumulate, not suitable for field decision making. Up to now, there is little research on mediators for field decision making and relative analysis.

In view of above problems in the studies of team decision making, this thesis: 1 ) tries to summarize the influencing factors on decision-making quality and divide the main influencing factors into team composition factors and team process factors, and researches the internal relationship between them; 2) researches the influencing mechanism of the main factors on decision-making quality during the process of field decision making, and constructs the conceptual model of "influencing factors-information sharing-decision-making quality" (see Figure 1). This model not only combines the main influencing factors correctly, but also exposes the "black box" between the influencing factors and decision-making quality in field decision making, which can make up for no relative research for the field decision making in the previous studies and provide a new interpretation for the influencing factors how to effect the team decision- 


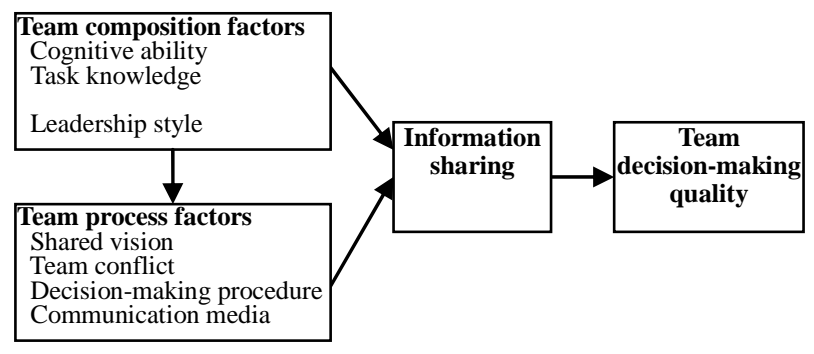

Figure 1. Conceptual model of influencing factors and influencing mechanism on team decision-making quality.

making quality.

\section{Information Sharing and Team Decision-Making Quality}

The team decision making was an "information exchanging project" for completing a task [5]. The characteristic of team field decision making is focusing on field communication and it makes different information sharing very important. Owing to the different status and responsibility in team, each team member will get different kinds of information. The information includes the common information that is known by all the members, and unique information that is only known by individual member. When team members sharing all information he knows with others, especially the unique information, all members will understand the task contents and aims deeply, and the quality of final decision will be improved. So, whether the information related with decision can be got smoothly and used effectively will influence the team decision-making quality directly.

In the "Information Sampling Mode", the sampling information was classified as shared information and unshared information. In the subsequent studies, Stasser proved the roles of unique information sharing on team decision making repeatedly. Stasser \& Stewart researched the unique information sharing time accounting for the proportion of the discussion time, and found the proportion was positively correlated with decision-making quality [3]. In 1998, Stewart \& Stasser introduced another testing method, separating the unique information mentioned at least once from all information mentioned at least once, and found in this method, the positive correlation of unique information sharing and decision-making quality was more remarkable [6]. Lu et al. made a metaanalysis of 21 studies, and considered whether the times of unique information mentioned or the times of unique information discussed was positive correlated with decision-making quality [7].

H1: Unique information sharing is positively correlated with team decision-making quality.

\section{Relationship of Team Composition Factors, Information Sharing and Team Decision-Making Quality}

Team composition factors refer to the factors that determined in the early days of the team, mainly including individual level of team members and leadership style. The individual level of team members includes the task knowledge got by the team members, their cognitive ability and so on. The leadership style can be usually divided into autocratic leadership and democratic leadership.

\subsection{Individual Level of Team Members}

As the input variable of team effectiveness, individual level of team members has been researched more than 50 years, lots of scholars thought the cognitive ability and task knowledge were the most important factors to forecast the individual job performance, and also the key resources of teams [8]. Zarnoth \& Sniezek found the higher the cognitive ability of individual was, the higher the team decision-making quality was [9]. Ellis thought the task knowledge got by the important team members had a great effect on the improvement of decision-making quality and performance [10].

H2a: Cognitive ability and task knowledge of team members are positively correlated with team decisionmaking quality.

Dennis J.D. considered that cognitive ability and task knowledge might influenced the information exchange in team at least two aspects [11]. High cognitive ability and task knowledge could help the members to do better personal recommendation on the basis of limited information, and also could help the members to strengthen the awareness of needing the important task information. These two aspects both could encourage more unique information sharing directly or indirectly. Harrison \& Pelletier thought through empirical study, that cognitive ability and task knowledge of team members could help team members to discuss the relevant information comprehensively from various perspectives [12]. The different views to strategy would provide a useful platform for members to discuss during the decision-making process [13].

H2b: Cognitive ability and task knowledge of team members are positively correlated with unique information sharing.

Combined with H1, we can establish the relationship of individual level of team members, information sharing and team decision-making quality.

H2c: Cognitive ability and task knowledge of team members have positive effects on team decision-making quality through the mediator of unique information sharing. 


\subsection{Leadership Style}

In the teams, leadership is an important and natural behavior, and has a prominent role on boosting problem solution, controlling orientation and time, esteeming opinion of team members and arousing team members' enthusiasm. Typical leadership could be classified as autocratic leadership or democratic leadership [14]. Autocratic leadership controlled team discussion, communication and task fulfillment; but democratic leadership promoted team discussion, and encouraged members to involve in the goal-setting process and fulfill the task [15]. In the team discussion, different leadership styles would have different effects on discussing process and final decision-making quality. Autocratic leadership didn't encourage team members to discuss, and the leader would express his opinions at the beginning of the decisionmaking process to govern others' choice. No discussion would have a bad effect on the decision-making quality and acceptance to decision. On the contrary, democratic leadership would give all members opportunity to express their opinions and make the decision based on the good communication. Thus, the decision-making quality and acceptance to the decision would be improved.

H3a: Democratic leadership can improve the team decision-making quality more than autocratic leadership.

During the team decision-making process, obtaining and using information were mainly completed through team discussion, and the team discussion was controlled and guided by the leader directly. So, the leadership style had a direct effect on information processing. Autocratic leadership style would make the leader's opinions and views on others' choice, and largely inhibit information communicating and processing, especially hinder the unique information sharing. On the contrary, democratic leadership style would encourage team members to speak their minds freely, improve the common and unique information mining and acceptance, and increase the utilization of information [16].

H3b: Democratic leadership can increase unique information sharing more than autocratic leadership. .

Combined with $\mathrm{H} 1$, we can establish the relationship of team leadership style, information sharing and team decision-making quality.

H3c: Democratic leadership can improves the team decision-making quality through the mediator of unique information sharing more than autocratic leadership.

\section{Relationship of Team Process Factors, Information Sharing and Team Decision-Making Quality}

Team process factors refer to the factors appeared and existed during the decision-making process, mainly in- cluding team shared vision, conflict, communication and so on.

\subsection{Shared Vision}

Shared vision is the core of team cooperation. It can make the members to interpret the task expectation accurately, and make the members' action to coordinate and adapt with other members' requirement. Only when the team members accepted the team developing orientation, they would cooperate and communicate with each other [17]. On the one hand, shared vision could contribute to task allocation among members and forming specialization. The higher degree of specialization and learning ability of team members were, the higher decisionmaking quality was. On the other hand, shared vision could increase the team cohesion, strengthen the coordination of individual's target and team target, and promote close cooperation of team members. The two roles could both improve the team decision-making quality and acceptance to decision [18].

H4a: Shared vision of team members is positively correlated with team decision-making quality.

Shared vision could improve the team members' energy, commitment and targets, and provide an orientation for members to communicate. It could increase information sharing among the team members, and contribute to high quality and professional information during the decision-making process. Under the direction of shared vision, task allocation would be more clear, which not only urged team members to dig for the unique information related to task, but also improve the quality of information during the decision-making process. Shared vision had an important role on team information processing ability.

H4b: Shared vision of team members is positively correlated with unique information sharing.

Combined with $\mathrm{H} 1$, we can establish the relationship of shared vision, information sharing and team decisionmaking quality.

H4c: Shared vision of team members has a positive effect on team decision-making quality through the mediator of unique information sharing.

\subsection{Team Conflict}

Team conflict could be divided into task conflict and relationship conflict [19]. Task conflict refers to the cognitive difference owing to the different views of task; relationship conflict refers to the pressure and frustration owing to individual difference, including more emotional factors [20]. Scholars usually considered that task conflict could largely promote team members to exchange the information and knowledge related to task and inspire 
new ideas, and it could also clear up some misunderstanding to enhance the recognition and understanding of task through communication. In a word, task conflict could improve the decision-making quality and team members' work performance [21,22]. However, Relationship conflict could evoke team members' negative emotions, such as, angry, tension, anxiety, pressure and frustration, and would make the working satisfaction declined and motivation lacked. Finally, relationship conflict would lead to team decision-making quality declined [22,23].

H5a: Task conflict is positively correlated with team decision-making quality.

H5b: Relationship conflict is negatively correlated with team decision-making quality.

In the decision-making teams, task conflict had the potential to increase the unique information sharing in that advocated of opposing viewpoints will be called on to describe and justify their positions [24]. In the metaanalysis, two methods for inducing task conflict that had received a fair amount of empirical attention were "Dialectical inquiry" and "Devil's advocacy" [25]. Both methods attempted to foster task conflict in decision-making teams by forcing members to question assumptions and confront minority positions. Several studies suggested these methods could lead to effective unique information sharing in teams [26]. However, relationship would evoke the negative emotions of members, and lead team members to battle over the parochial views of individuals or coalitions rather than consolidating the set of information available into a more complex but accurate whole. In other words, relationship conflict might prevent teams from effectively incorporating the unique information [20].

H5c: Task conflict is positively correlated with unique information sharing.

H5d: Relationship conflict is negatively correlated with unique information sharing.

Combined with H1, we can establish the relationship of team conflict, information sharing and team decisionmaking quality.

H5e: Task conflict has a positive effect on team decision-making quality through the mediator of unique information sharing.

H5f: Relationship conflict has a negative effect on team decision-making quality through the mediator of unique information sharing.

\subsection{Decision-Making Method}

Timmermans divided the team decision-making procedure into MAU (multi-attribute utility) decision support and unstructured discussion [27]. MAU model was widely used in decision support, and it supplied a framework of decision problems and a logic order of decision. MAU integrated the interaction of team members as a whole, reduced the negative emotions of group dynamics (e.g.: the dominant position of one or more members in discussing process; low tolerance for the minority view) and improved team decision-making performance. Timmermans studied how MAU effected decision-making quality and found MAU had a remarkable effect on subjects' preference and team consensus, and also had a good effect on members' satisfaction to decision-making process [27].

H6a: MAU decision support can increase team decision-making quality more than unstructured discussion.

MAU model provided an analysis support to assess the merits of each alternative and made the members' preference and the inconsistency clear, and it improved the different information sharing and exchanging in teams [28]. MAU required all team members to discuss all information and express their viewpoints and could dig for and utilize more unique information than unstructured discussion.

H6b: MAU decision support can increase unique information sharing more than unstructured discussion.

Combined with H1, we can establish the relationship of team decision-making method, information sharing and team decision-making quality.

H6c: MAU decision support can increase team decision-making quality through the mediator of unique information sharing more than unstructured discussion.

\subsection{Communication Media}

With the development of computers and network, many scholars began to learn the effect of communication media on team decision-making quality. Scholars compared the decision-making difference under the conditions of CMC and FTF, but the results were different. Some scholars considered that CMC could increase the decision-making quality more than FTF. Because under the condition of FTF, the opinions of experts of higher status could become the mainstream, the other members just participated passively. So, it would lead to groupthink. But under the condition of CMC, owing to lacking of social context clues, members would be more equal. Thus, the teams would generate more thoughts and ideas. Rock \& Ayman thought without the interference of nonlanguage information, members would focus on the information processing during the discussion [29]. So, CMC could pre-determinate the successful decision better than FTF. However, some scholars got the opposite conclusions. Hightower \& Sayssed found under the condition of CMC, members would discuss more common information rather than unique information, and owing to lacking of non-language information, communication 
and task fulfillment under CMC was more difficult than under FTF [30]. This thesis is inclined to choose the first opinion.

H7a: CMC can increase team decision-making quality more than FTF.

Some scholars thought under the condition of CMC, members might share their unique information at the same time, and would avoid the situation that some members occupied much discussing time to hamper other members to express views or influent the thought of other members [31]. Equal status of members under CMC would be better for members to participate discussion actively and share their common and unique information.

H7b: CMC can increase unique information sharing more than FTF.

Combined with H1, we can establish the relationship of communication media, information sharing and team decision-making quality.

H7c: CMC can increase team decision-making quality through the mediator of unique information sharing more than FTF.

\section{The Internal Relationship between Team Composition Factors and Process Factors}

The above analyze and summary the influencing mechanism of team composition factors and team process factors on decision-making quality. In fact, team composition factors not only can influence the final decisionmaking quality directly, but also can influence the decision-making quality indirectly through team process factors. So, paying more attention to the effects of team composition factors on team process factors usually is very important to final decision-making quality.

Mohammed \& Ringseis found during the team interactive process, cognitive difference related to task had a direct effect on conflict [32]. Cronin \& Weingart put forward "conflict based on mental representation gap", and pointed out in their research that function diversification would increase members' cognitive difference and would lead to members' interpretation to the necessary information different [33]. Members' mental representation gap was the source of conflict. Hambrick, Cho \& Chen certificated through empirical research that cognitive difference would benefit for mobilizing the member to solve the task from multi-viewpoints and stimulate the task conflict [34].

H8: Team members' cognitive difference is positively correlated with task conflict.

Compared with autocratic leadership, democratic leadership could benefit for encouraging team members to express their different opinions related to task, and forming the mechanism of free expression of doubt in teams.
On the other hand, democratic leadership also could benefit for establishing a harmonious atmosphere in teams and reducing the negative effect of conflict. Lovelace, Shapiro \& Weingart certificated in their study that democratic leadership could encourage team members express the doubt related to task freely, resolve violent conflicts in time, and play an active role in the team members interaction [35].

H9a: Democratic leadership can increase team task conflict more than autocratic leadership.

H9b: Democratic leadership can reduce team relationship conflict more than autocratic leadership.

There were two basic ways to establish shared vision: one was through the active initiative of leaders and acceptance of team members, the other was through the collection of team members' visions. No matter what kind of way, leadership had an important role on establishing shared vision. During the process of establishing shared vision, the opinions of members might be different. So, the leaders should keep touch with team members at any time, and help members rather than control them. Refining and publicity for shared vision should be established on the basis of freedom, sincerity and communication. So, democratic leadership makes it easier for members to accept shared vision.

H10: Democratic leadership can push shared vision ahead easier than autocratic leadership.

\section{Conclusion and Limits}

This thesis puts forward the conceptual model of team composition factors, team process factors, unique information sharing and team decision-making quality, and infers that team composition factors of individual level, leadership style and team process factors of shard vision, team conflicts, decision-making methods, and communication media influence decision-making quality through the mediator of unique information sharing. This model includes many major influence factors on decision-making quality, exposes the "black box" between the influencing factors and decision-making quality during the field decision making, and analyzes deeply the role of unique information sharing between influencing factors and decision-making quality. This research will give decision makers some suggestion and reference of how to increase decision-making quality.

\subsection{Strengthen Information Sharing in Teams and Encourage Team Members to Communicate and Think about the Unique Information}

During the field decision making, the most important factor of high quality decisions was the information 
sharing and communication in the field. Exchange and integration of different information could not only improve the individual bias and asymmetric information, but also stimulate the new ideas effectively. But in reality, owing to the biased sampling, team members usually discussed the shared information rather than the unique information, and it made teams of many experts not to produce high quality decision. Therefore, how to strengthen unique information sharing and communicating is most important. Changing composition factors and strengthening process factors can stimulate the unique information sharing in part.

\subsection{Pay Enough Attention to Team Composition Factors as Much as Team Process Factors}

Previous studies under IPO frame considered that team process factors were the main influencing factors on team performance, and ignored the effect of team composition factors. However, recent studies certificated that composition factors not only can influence the unique information sharing and final decision-making quality directly, but also can influence the decision-making quality indirectly through team process factors. So, we should think about the different roles of team composition factors and team process factors and the internal relationship between them, and not favor one or discriminate against the other.

The model of "influencing factors-information sharing - team decision-making quality" mainly thinks about the internal conditions of teams, and does not consider the external conditions of teams. In fact, under the different external conditions, the influential way of each kind of influencing factors would be different. In the future studies, we should research the influence of team composition factors and team process factors on decision-making quality combined with the external dynamic environment.

\section{REFERENCES}

[1] N. L. Kerr and R. S. Tindale, "Group Performance and Decision Making,” Annual Review of Psychology, Vol. 55, No. 1, 2004, pp. 623-655. http://dx.doi.org/10.1146/annurev.psych.55.090902.1420 $\underline{09}$

[2] G. Stasser, "Computer Simulation as Research Tool: The Discuss Model of Group Decision-Making," Journal of Applied Social Psychology, Vol. 23, No. 5, 1988, pp. 126139.

[3] G. Stasser, "Information Salience and the Discovery of Hidden Profiles by Decision-Making Group: A 'Thought Experiment'," Organizational Behavior and Human Decision Processes, Vol. 52, No. 1, 1992, pp. 156-181. http://dx.doi.org/10.1016/0749-5978(92)90049-D
[4] J. R. Larson, P. C. Foster-Fishiman and C. B. Keys, “Discussion of Shared and Unshared Information in DecisionMaking Groups,” Journal of Personality and Social Psychology, Vol. 67, No. 3, 1994, pp. 446-461. http://dx.doi.org/10.1037/0022-3514.67.3.446

[5] G. DeSancits and R. B. Gallupe, "A Foundation for the Study of Group Decision Support System,” Management Science, Vol. 33, No. 5, 1987, pp. 589-609. http://dx.doi.org/10.1287/mnsc.33.5.589

[6] D. D. Steward and G. Stasser, "The Sampling of Critical, Unshared Information in Decision-Making Group: The Role of an Informed Minority,” European Journal of Social Psychology, Vol. 28, No. 1, 1998, pp. 95-113. http://dx.doi.org/10.1002/(SICI)1099-0992(199801/02)28 :1<95::AID-EJSP847>3.0.CO;2-0

[7] L. Lu, Y. C. Yuan and P. L. Mcleod, “Twenty-Five Years of Hidden Profiles in Group Decision Making: A MetaAnalysis,” Personality and Social Psychology Review, Vol. 16, No. 1, 2012, pp. 54-75. http://dx.doi.org/10.1177/1088868311417243

[8] J. A. LePine, J. R. Hollenbeck, et al., "Effects of Individual Differences on the Performance of Hierarchical Decision-Making Teams,” Journal of Applied Psychology, Vol. 82, No. 5, 1997, pp. 803-811. http://dx.doi.org/10.1037/0021-9010.82.5.803

[9] P. Zarnoth and J. A. Sniezek, "The Social Influence of Condidentce in Group Decision Making,” Journal of Experimental Social Psychology, Vol. 33, No. 4, 1997, pp. 345-366. http://dx.doi.org/10.1006/jesp.1997.1326

[10] A. P. Ellis, "System Breakdown: The Role of Mental Models and Transactive Memory in the Relationship between Acute Stress and Team Performance," Academy of Management Journal, Vol. 49, No. 3, 2006, pp. 576-589. http://dx.doi.org/10.5465/AMJ.2006.21794674

[11] J. D. Dennis, "Effects of Cognitive Ability, Task Knowledge, Information Sharing, and Conflict on Group Decision-Making Effectiveness,” Small Group Research, Vol. 30, No. 5, 1999, pp. 608-634.

[12] E. F. Harrison and M. A. Pelletier, "Foundations of Strategic Decision Effectiveness,” Management Decision, Vol. 36, No. 3, 1998, pp. 147-159.

http://dx.doi.org/10.1108/00251749810208931

[13] B. J. Olson, S. Parayitam and Y. J. Bao, "Strategic Decision Making: The Effects of Cognitive Diversity, Conflicts and Trust on Decision Outcomes," Journal of Management, Vol. 33, No. 2, 2007, pp. 196-222. http://dx.doi.org/10.1177/0149206306298657

[14] K. Lewin, R. Lippit and R. K. White, "Pattens of Aggressive Behavior in Experimentally Created 'Social Climates',” Journal of Social Psychology, Vol. 10, 1939, pp. 271-279.

[15] M. G. Cruz, D. D. Henningsen and B. A. Smith, "The Impact of Directive Leadership on Group Information Sampling, Decision, and Percetions of the Leader," Communication Research, Vol. 26, No. 3, 1999, pp. 349-369. http://dx.doi.org/10.1177/009365099026003004

[16] E. Kushell and R. Newton, “Gender, Leadership Style and Subordinate Satisfaction: An Experiment,” Sex Roles, Vol. 
14, No. 3-4, 1986, pp. 203-209. http://dx.doi.org/10.1007/BF00288249

[17] McKee, “An Organizational Learning Approach to Product Innovation,” Journal of Product Innovation Management, Vol. 9, No. 3, 1992, pp. 235-245.

[18] R. S. Dooley and G. E. Fryxell, “Attaining Decision Quality and Commitment from Dessent: The Moderating Effects of Loyalty and Competence in Strategic Decision Making Teams,” Academy of Management Journal, Vol. 42, No. 4, 1999, pp. 389-402. http://dx.doi.org/10.2307/257010

[19] K. A. Jehn, "Enhancing Effectiveness: An Investigation of Advantages and Disadvantages of Value-Based Intragroup Conflict," International Journal of Conflict Management, Vol. 5, No. 3, 1994, pp. 223-238. http://dx.doi.org/10.1108/eb022744

[20] A. C. Amason, "Distinguishing the Effects of Functional and Dysfunctional Conflicts on Strategic Decision Making: Resolving a Paradox for Top Management Teams,” Academy of Management Journal, Vol. 39, No. 1, 1996, pp. 123-148. http://dx.doi.org/10.2307/256633

[21] K. A. Jehn, "A Multimethod Examination of the Benefits and Detriments of Intragroup Conflict," Administrative Science Quarterly, Vol. 40, No. 2, 1995, pp. 256-282. http://dx.doi.org/10.2307/2393638

[22] O. Jansssen, E. Van de Vliert and C. Veenstra, "How Task and Person Conflict Shape the Role of Positive Interpdependence in Management Groups,” Journal of Management, Vol. 25, No. 2, 1999, pp. 117-141. http://dx.doi.org/10.1016/S0149-2063(99)80006-3

[23] T. W. Porter and B. S. Lilly, "The Effects of Conflicts, Trust and Task Commitment on Project Team Performance," International Journal of Conflict Management, Vol. 7, No. 4, 1996, pp. 361-376. http://dx.doi.org/10.1108/eb022787

[24] D. Tjosvold, "Managerial Implications of Controversy Research," Journal of Management, No. 11, 1985, pp. 221-238.

[25] C. R. Schwenk, "Effects of Devil’s Advocacy and Dialectical Inquiry on Decision Making: A Meta-Analysis,” Organizational Behavior and Human Decision Processes, Vol. 47, No. 1, 1990, pp. 161-176. http://dx.doi.org/10.1016/0749-5978(90)90051-A

[26] D. M. Schweiger, W. R. Aandberg and J. W. Ragan, “Group Approaches for Improving Strategic Decision Making: A
Comparative Analysis of Dialectical Inquiry, Devil's Advocacy and Consensus," Academy of Management Journal, Vol. 29, No. 1, 1986, pp. 51-71.

http://dx.doi.org/10.2307/255859

[27] D. Timmermans and C. Vlek, "Effects on Decision Quality of Supporting Multi-Attribute Evaluation in Groups," Organizational Behavior and Human Decision Process, Vol. 68, No. 2, 1996, pp. 158-170. http://dx.doi.org/10.1006/obhd.1996.0096

[28] G. DeSancits and R. B. Gallupe, "A Foundation for the Study of Group Decision Support Systems,” Management Science, Vol. 33, No. 5, 1987, pp. 589-609. http://dx.doi.org/10.1287/mnsc.33.5.589

[29] S. G. Rock, et al., "Group Decision Making and Perceived Decision Success: The Role of Communication Medium," Group Dynamics, Vol. 9, No. 1, 2005, pp. 1531. http://dx.doi.org/10.1037/1089-2699.9.1.15

[30] R. Hightower, et al., "The Impact of Computer-Mediated Communication Systems on Biased Group Discussion," Computers in Human Behavior, Vol. 11, No. 1, 1995, pp. 33-44. http://dx.doi.org/10.1016/0747-5632(94)00019-E

[31] S. K. Lam and J. Schaubroeck, "Improving Group Decision by Better Pooling Information: A Comparative Advantage of Group Decision Support System," Journal of Applied Psychology, Vol. 85, No. 4, 2000, pp. 565-573. http://dx.doi.org/10.1037/0021-9010.85.4.565

[32] S. Mohammed, et al., "Team Mental Models in a Team Knowledge Framework: Expanding Theory and Measurement across Disciplinary Boundaries,” Journal of Organization Behavior, Vol. 22, No. 2, 2001, pp. 89-106.

[33] M. A. Cronin and L. R. Weingart, "Representational Gaps, Information Processing and Conflict in Functionally Diverse Teams," Academy of Management Review, Vol. 32, No. 3, pp. 761-773. http://dx.doi.org/10.5465/AMR.2007.25275511

[34] D. C. Hambrick, T. S. Cho and M. J. Chen, "The Influence of Top Management Heterogeneity on Firm's Competitive Moves," Administrative Science Quarterly, Vol. 41, No. 4, 1996, pp. 659-684. http://dx.doi.org/10.2307/2393871

[35] K. Lovelace, et al., "Maximizing Cross-Functional New Product Teams' Innovativeness and Constraint Adherence: A Conflict Communications Perspective," Academy of Management Journal, Vol. 44, No. 4, 2001, pp. 779-793. http://dx.doi.org/10.2307/3069415 